\title{
A QUALITATIVE STUDY EXPLORING THE EXPERIENCES AND VIEWS OF MOTHERS, HEALTH VISITORS AND FAMILY SUPPORT CENTRE WORKERS ON THE CHALLENGES AND DIFFICULTIES OF PARENTING
}

\author{
Authors \\ Linda Bloomfield MSc, BSc (Hons), University of Hertfordshire \\ Professor Sally Kendall PhD, BSc (Hons), RGN, RHV, University of Hertfordshire \\ Liz Applin, BSc, RGN, HV Watford and Three Rivers PCT \\ Vicky Attarzadeh RGN, RHV, Watford and Three Rivers PCT \\ Katie Dearnley, MACP, MSW, MPhil, BA, Peace Childrens Centre \\ Louise Edwards RGN, RHV, Children Schools and Families, Fleetville and St Albans \\ and Harpenden PCT \\ Linda Hinshelwood RGN, SCM, HVdip, Watford and Three Rivers PCT \\ Pat Lloyd BSc,RHV,RN, Watford and Three Rivers PCT \\ Teresa Newcombe RGN, RHV, PGdip, Hertsmere PCT
}

Correspondence

Linda Bloomfield

Research Fellow

CRIPACC

University of Hertfordshire

College Lane

Hatfield

Hertfordshire

AL10 9AB

UK

e-mail: 1.j.bloomfield@herts.ac.uk 


\begin{abstract}
Successive policy documents have referred to the need to support parents as an approach to reducing social exclusion, behaviour problems among young people and crime rates. Much of the rhetoric focuses on professional intervention, and there is less attention paid to the views and experiences of parents themselves.

This study explores the experiences and views of mothers, health visitors and family support centre workers who work with parents, on the challenges and difficulties of parenting children under the age of six. It provides an appreciation of their views on effective parenting and how parents can be helped to feel more effective in the parenting role.
\end{abstract}

Focus groups, which were exploratory and interactive in form, were conducted across three Primary Care Trusts in Hertfordshire. Three samples were purposively selected in order to examine the range and diversity of experiences and views about parenting and included parents of children up to the age of six, health visitors and family support centre workers. Mothers were those waiting to attend a parenting programme and included first time mothers and those with more than one child. Health visitors and family support workers had a range of experience in working with parents and children and included those who were facilitating parenting programmes and those who were not.

A number of themes emerged surrounding the challenges and difficulties of parenting and effective parenting including expectations of others, establishing routines, play, behavioural issues and discipline, empathy and communication. Similar themes 
emerged from all groups, however there were qualitative differences between parents and professionals in the way these issues were expressed.

Key statements from the parent focus groups have been developed into self-efficacy statements, which will be used as input to the development of a tool to measure the effectiveness of parenting programmes.

Keywords: focus groups, parenting, self-efficacy, challenges, difficulties 


\section{Introduction}

Whilst there has been increasing interest by government in supporting parents and promoting better outcomes for children through professional support of families in the community, (Acheson et al., 1998, Department for Education and Skills, 2003, Home Office, 1998, Secretary of State for Health, 1999, SureStart, 2001) there is less research evidence of the views and experiences of parents themselves. For example the recent green paper 'Every Child Matters' (Department for Education and Skills, 2003) refers particularly to the need to be responsive to families through education, health and social services, with an emphasis on professional intervention.

Parents are key to ensuring the healthy physical, social, emotional and cognitive development of their children(Ehrensaft et al., 2003, Brody et al., 1999, Cunningham \& Boyle, 2002, Serketich \& Dumas, 1996). Behaviour problems in early childhood have been associated with later difficulties including criminal behaviour, drug and alcohol abuse and mental health problems with parenting and family interaction reported to account for $30-40 \%$ of the variation in anti-social behaviour in children (Gibbs et al., 2003, Barlow, 1999, Patterson et al., 1989). Equally, a parent who perceives their child to have behaviour problems, or one who feels inadequate to fulfil parenting roles, may develop feelings of frustration, guilt, stress, anger and depression (Gross et al., 1995, Long et al., 2001, Donovan et al., 1990, Chiariello \& Orvashel, 1995, Jackson \& Huang, 2000, Kwok \& Wong, 2000, Gross et al., 1994).

Within policy and practice, it is increasingly being recognised that parents may need support in the parenting role and this has responded in a growth in the adoption of 
numerous parenting training programmes for health visitors and community practitioners who provide sources of support to parents. For example, since 1996 parenting programmes based on skill acquisition, relationships, behaviour management, parent education and support have been organised and facilitated within West Hertfordshire Primary Care Trusts (PCTs) in collaboration, or in direct partnership, with Children, Schools and Families through the Family Support Centres. Although programmes vary in their philosophy and content, the general ideology underpinning parenting programmes is to help parents become problem solvers who understand the effects of their behaviour on their children and who feel empowered and confident in their parenting role (Gaze, 1997, Miller \& Sambell, 2003). Typical reasons reported by parents for participating in a programme include, to establish new ways of dealing with demanding behaviour, to be a good parent and to exchange ideas with other parents (Barlow \& Stewart-Brown, 2001), for advice and guidance, dealing with behaviour problems and discipline, self-control, making time for themselves and their children and coping with children's medical problems and accidents (Long et al., 2001). A UK study that compared the perspectives and goals of major stakeholders in the programmes reported the most frequently mentioned expected outcomes to be better relationships with the children, greater knowledge, emotional benefits and sharing experiences (Grimshaw \& McGuire, 1998).

Whilst a range of type of programmes is offered, there is recognition that there is a significant lack of evidence about their outcomes. The research evidence is mostly anecdotal and based on self-reports by parents and programme facilitators. It is important to find out which interventions are of most benefit to parents and their children and indeed which elements of these programmes have the most impact on 
short and long-term outcomes. To deliver effective parenting initiatives it is important to ascertain what parents perceive to be the major challenges they face in the parenting role and the greatest difficulties they encounter. Recent research has highlighted parenting self-efficacy beliefs, a parent's self-estimations of competence in the parenting role, as a central correlate of parenting behaviour and evidence suggests that self-efficacy beliefs may mediate the effects of a number of parent and child variables on the quality of parenting (Coleman \& Karraker, 1997, 2000, Cutrona \& Troutman, 1986, Raver \& Leadbeater, 1999, Teti \& Gelfand, 1991). Research evidence on parents’ beliefs about their competence in the parenting role may guide professionals who are in a position to support them.

This qualitative study provides an in-depth understanding of the opinions and experiences of mothers waiting to attend parenting programmes and of parenting programme facilitators. Focus groups were conducted to identify the major challenges faced by parents of children under the age of six. We wanted to find out what difficulties parents experience in the parenting role and whether those difficulties are shared by all parents or differ at various stages of parenting and between cultures, and social groups. Also of interest was the notion of 'effective parenting' and ways in which health visitors and family centre workers might help parents to achieve effective parenting skills. Focus groups were used rather than one to one interviews as people more often reveal sensitive information when they feel they are in a safe and comfortable environment with people like themselves. The focus group provides a natural environment where participants influence and are influenced by others and where the moderator can derive understanding based on the discussions as they develop (Krueger \& Casey, 2000). Moreover focus groups allow collective discussion with the 
population of interest around a particular phenomenon and hence provide a deeper understanding of the topic under study (Willgerodt, 2003). They provide insights into the perceptions and points of view of people who have common characteristics related to the research topic while allowing an appreciation of the variation in experiences (Willgerodt, 2003, Morgan, 1998). The focus group data from this study will be used as input to a parenting self-efficacy instrument as a means of evaluating parenting programmes and will be phrased in the language and terminology used by parents who attend such parenting programmes. Within focus groups the researcher is able to determine how the phenomenon is uniquely perceived and expressed, which may aid the process of generating items for an instrument that are meaningful and relevant to the population of interest.

\section{Methods}

\section{Participants}

Three samples were purposively selected for the focus groups, to include parents of children up to the age of six, health visitors and family support centre workers. 70 participants took part in 12 focus groups. The samples were selected to provide a range and diversity of experience and opinions of those facilitating parenting programmes, and of parents waiting to attend parenting programmes. Participants were from a range of environments across three Primary Care Trusts (PCTs) to cover a breadth of experience, knowledge, attitudes, behaviour and location (Burgess, 1994, Holloway \& Wheeler, 1996, National Centre for Social Research, 1999). Parents included first time mothers and those with more than one child. Health visitors and family support workers 
had a range of experience in working with parents and children and included those who were facilitating parenting programmes and those who were not.

For this study the research team developed interview guides that identified core topics, gathered from extensive review of the parenting literature and from the experiences and observations of health visitors, to be included in all the focus groups. These topic guides were developed to explore what the major difficulties are surrounding parenting at different stages of being a parent from infancy through to school entry. These included the major challenges of parenting, specific difficulties of parenting, what is considered to be effective parenting and ways in which to improve parenting effectiveness and confidence. The topic guides were used as briefing documents for the focus groups.

Ethics approval was granted by the Local Research Ethics Committee. Each focus group was facilitated by the same interviewer and co-facilitated by another member of the research team. Parents were mostly recruited from parenting programme waiting lists across three PCTs; each was sent an information leaflet outlining the study and a consent form and questionnaire to complete and return to the researcher. The questionnaire requested contact details and information pertaining to the parents' age, marital status, number and ages of children, current and previous occupation and ethnic origin. Permission was requested to contact consenting parents by telephone ten to fourteen days later to arrange the focus group. The researcher contacted all parents to explain in detail the purpose of the focus group and the nature of questions that would be discussed. The young mother's group and the Asian women's group were recruited by family support workers who were in direct contact with these parents and they were 
not on waiting lists to attend parenting programmes. Focus groups were conducted at family support centres and health clinics and signed consent was obtained beforehand. Health visitors and family support workers were recruited at their place of work and the focus groups were scheduled to take place following regular team meetings. Verbal consent was obtained beforehand and signed consent obtained on the day of the focus group. All focus groups were conducted in private and were tape-recorded; anonymity and confidentiality were explained and assured. Each focus group took between fortyfive minutes and ninety minutes.

The focus groups were transcribed verbatim and a matrix based approach to thematic analysis used to allow between and within group analysis (Bryman \& Burgess, 1994). The transcripts for each focus group were analysed independently by one researcher and cross-checked by another for consistency and rich interpretation, that is for inclusion of all new information. A content analysis, which identified constructs and allowed data to be classified, was conducted for each sample (National Centre for Social Research, 1999). Thematic charts were constructed based on the themes central to each sample. Areas of agreement or diversity of opinion between focus groups were identified.

\section{Findings}

Five parent focus groups were conducted including an Asian women's group and a group of young and mostly single parents $(n=26)$, three health visitor groups $(n=19)$ and four family centre worker groups $(n=25)$. Parents, who were all mothers (although fathers were invited), were from a wide range of socio-economic and educational backgrounds and had an age range of 18-48 years, mean age 35.4 years. Half of the 
parents had attended post compulsory education, $40 \%$ were working either full or parttime and $80 \%$ were car owners. One fifth of the mothers were single parents. In total 70 participants took part in the twelve focus groups, of which two were male.

A number of themes emerged from the analysis of transcripts. These themes were grouped into three main categories that related to the core focus group topics; the challenges of parenting, specific difficulties of parenting and effective parenting.

\section{The challenges of parenting}

The results show that mothers, health visitors and family support workers identified a range of issues surrounding the challenges of parenting (Box 1).

\section{Insert Box 1}

\section{Expectations and Pressures}

Many of these themes were reflected across all focus groups. Health visitors, in particular, said there was a lot of pressure on parents to meet other people's expectations and that pressure from other family members, especially in-laws, to do things a different way was a major challenge to mothers "mothers-in law, fathers-in law...they have their own agenda for what this mum should be doing...it can actually cause quite a lot of conflict... there's a lot of pressure, an awful lot of pressure" (HV2). 
There was a concern from parents that they needed to be seen to be bringing up perfect children and a tendency to focus on other people's opinions of you as a parent "you know, everyone's got their little say, even complete strangers when you're shopping oh I think he needs a bottle - that's the challenge for me, other people's - what other people are saying to me, the pressures that they put on you, especially in-laws" (P1). Some mothers said they were continually comparing themselves to other parents and feeling that they were perhaps not doing as well as they should "there is so much pressure on us as parents to be the perfect parent, to be seen to be bringing up perfect children, to run a nice home and to be the perfect wife, the list is endless on the pressures I think, well that is how I feel on being a parent, and sometimes I just feel I can't do this I can't be perfect" (P3). Family support workers also said that mothers often perceive themselves to be not coping as well as other parents and that this led to feelings of failure "and yes there is that sense of failure because there is a sort of culture expectation that women can do it" (FW2). It was generally felt by all groups that cultural expectations create pressure for women to be seen to be the perfect parent and that children should be seen to be good, to be successful at school and to have the latest trainers and the latest toys.

\section{Play, Managing Time, Routines}

Many mothers said they felt under pressure for their children to do this group and that group and that it was difficult to find a quiet time to read stories or just sit and cuddle their children "I can't just sit down and cuddle with him, you know I have to cook a meal, do the cleaning and things like that" (P3). One or two mothers also said their partners played more with the children "it is easy to just let them (partners) do the nice things, playing with the kids while you quickly go and do this" (P2). Some professionals 
also said that mothers felt a need to stimulate the child almost constantly and that they often didn't know how to do basic play, talking, listening and just sitting with the children "parents have forgotten or never know how to actually play with their child...everything is so pre-packed for everyone" (HV1), "don't actually realise how important play is" (FW4).

Being pulled in all directions' was a common theme and many mothers said it was very difficult to establish a routine or find a routine that works. One said that planning for an enjoyable day out was a major task "planning is quite key really in so far as having an enjoyable day because you have to work out meals and sleeps and you know where you are going to go and what you are going to do...make sure you have got everything with you, everything but the kitchen sink" (P2), and another that it was difficult to feel they ever achieved anything. However, one mother said her child would fit into her own life "I'm almost the reverse. I was always very organised and methodical and structured at work and I've always said this child's going to slot into my life, and I just pick her up and under my arm and off we go" (P1) and another said that she would adjust as the child develops. Professionals said that parents often had difficulty in juggling everyone's needs, and at times neglected to meet their own needs and to look after themselves "you become a parent and you, along the way, forget how to look after yourself and I think that's a common thing that people forget that they need to look after themselves as well" (FW1). Mothers said there was rarely time for themselves, that they sometimes needed a break, "a bit of space” (P1), "Ifeel as though I have lost power because I don't have anything to add other than just being the mum at home and so on, I feel too dependent on the situation" (P3). However, it was said amongst the young mother's group that there was not enough to do to fill their day and 
some felt very isolated and bored at home with their child "I've got too much time really, sometimes I'm sitting there thinking... if she's asleep I get really bored, I'm like I've done the housework so there's not really much to do, just sit there" (P5).

\section{Prepared for Parenthood}

It was suggested by all groups that nothing prepares you for motherhood and that for some a new baby can be an overwhelming sense of responsibility "I think a lot of people feel they're changed by that overwhelming sense of responsibility that you can't sort of anticipate really until they are faced with this very, you know, small, vulnerable baby"(HV2), "I got home with the baby and it was like well, what do we do now" (P1). Mothers generally agreed that first time round is hard, that your whole world changes, "you have been an independent person and you have a baby and your whole world changes" (P3), and for some it was not how they thought it would be, "nothing prepared me, it was a total shock; I just couldn't believe how much life had changed" (P1). There was some agreement that second time round was a easier, "when I had the second baby it was much easier, because I think I handled him much better" (P1) and "With the first one you weren't sure about anything. Even bathing the baby, feeding them, you weren't sure about anything, you looked at books after books” (P2). Health visitors and family support workers expressed concerns that society expects mothers to know instinctively what to do but for some people parenting doesn't come naturally and a mother may feel insecure in her new role, "and the mother is somehow insecure in her role so she doesn't know what to do" (HV2).

'Just getting through the day' was a common theme between all groups with single parents finding this a particular challenge "because I'm on my own it's having to do like the mum and the dad role so it's getting it all in one day. It's shattering sometimes" 
(P5) and for some mothers, coping without their own parents nearby was difficult, "I haven't got no parents near...sometimes I find it very, very difficult, very stressful" (P2).

\section{Consistent parenting}

Many of those interviewed said that when both parents are in disagreement about parenting style it is difficult to be consistent in disciplining children, though most agreed on the importance of consistency "I find it easier when I am disciplining them on my own, if he (husband) is not there, I find it easier" (P2). This was a particular issue for the young mother's group, especially for those who were separated from the child's father, 'I'm saying don't hit back, but when he goes to his dad's, he's saying hit back so it's really difficult. He's just confused...but then he's seen his dad hit me so he probably thinks it's ok anyway" (P5).

\section{Cultural expectations}

In addition to the challenges expressed by all groups, the Asian women talked about several issues specific to themselves. "we want to make sure that our children fit into this society as well as our society, so they get equal balance and we feel that there's so much pressure on us to fit into those, to get that equal balance" (P4), "to give them the best of both worlds"(P4). It was very important to these parents that their children grow up having a respect for both the East and the West and they said this created tension within the family, "you see our children hate us more because they think we put a lot of pressure on them" (P4).

Cultural expectations were seen to be a major challenge for many parents who struggle without the close family network from their own cultural background, "because the expectations of being here are very different from their own family experiences, some 
parents can't make that adjustment very well' (FW2). It was recognised that this created a loss of confidence in some Asian women, "when they've come from one country, moved into another culture and have changed the traditional methods of feeding, they seem to have lost their confidence about the way of feeding" (HV2).

\section{Specific difficulties of parenting}

Parents and professionals identified a number of specific difficulties associated with parenting children under six years of age Box 2. Although the issues raised were broadly the same across all groups, there were qualitative differences in the way these issues were expressed and the degree of importance given to them. Whereas health visitors and family support workers more often emphasised boundary setting and behavioural issues, parents consistently talked about understanding and empathising with their children, sensing the child's mood and general concerns around control and discipline.

\section{Insert Box 2}




\section{Boundaries}

Setting boundaries raised a number of issues amongst professionals, concerning both the setting of boundaries and maintaining them, "setting boundaries and if they can maintain them and not feel guilty about maintaining the boundaries because of social pressure” (HV1), “ a lot of parents find it difficult to put in boundaries... and they are not consistent, they will try something and give up after the first day and just say it doesn't work" (HV3), "how do you put in boundaries that are loving and safe boundaries...it is hard to see that boundaries can be loving" (FW2), "children pushing the limits of the boundaries...parents not being able to cope with that" (FW3).

\section{Behaviour}

The consensus among health visitors and family support workers was that behaviour problems particularly over mealtimes and bedtimes was a difficulty for many parents, “ he won't get dressed, he won't get up, he won't go to school" (FW1), "he won't sit at the table to eat meals, he won't sit still", "he won't go to bed, he won't listen" (FW1), "every step of the way becomes a battle" (HV1). It was said that these problems often developed because parents felt unable to say 'no' to their child "they give in to them, they don't persevere with them" (FW3), "they can't say 'no' to the children" (FW3), "I am going to say no don't do that but the child knows it can push and push" (HV1).

\section{Discipline}

Parents did not talk specifically about setting boundaries, however discipline was a concern, particularly how far to go with discipline and how disciplining their child made them feel, "and if I shout at him, I hate myself for shouting at him" (P3), "you don't know when to let things go and when to bring them up on it and say - right you have to stop that" (P3), "you're made to feel very guilty now if you're cross about 
anything" (P1), "I've a few times said, now I'm going to smack you, because that's all I've got left and I really don't want to go down that road" (P1), "you have to be really strong and then you are being the disciplinarian again" (P2). The young parents group focused on discipline as an issue, in particular physical punishment, "I don't actually smack him, I threaten to smack him and that's just as hard for him to cope with. You know - if you don't do that now I'm going to smack your bottom, pull your pants down" (P5), 'I don't smack her, I just tap her on the hand but I find I'm doing it every day and I don't know how else to tell her off' (P5).

\section{Handling conflicts}

The majority of parents said they knew how they should behave when handling conflicts with their children but many found it difficult to be consistent, "if I am not strong enough I will just let him get away with it" (P2), "you are supposed to be consistent, but there are times..." (P2). Parents said they found themselves frequently battling with their children and that the children were often difficult to handle, "it's just all these battles, I find I battle a lot" (P1), "he can handle me far better than I can handle him", (P1), "I have a feeling, it's quite horrible to say it about my own child, but

I think he is quite good at manipulating (if he can't get his own way)" (P3), "I have a problem with my four year old going to the toilet...so I am sort of battling with her... and she knows that is the one thing that really winds me up" (P2).

\section{Communication}

The ability to communicate with their child, and to have understanding and empathy with their child was of great concern to nearly all parents. Some parents experienced difficulty in communicating with and interpreting their child's mood "when he's not happy I don't feel particularly happy" (P1), "I have absolutely no idea what his cry 
means, I just look at his face and think is it a red angry face, a bright happy face...I don't know...I've absolutely no idea" (P1), "I cannot get through to him; what really hurts me most is I actually care about him and it really breaks my heart" (P3). For other parents, understanding their child was not an issue, "I know and recognise the cry and just respond to that" (P1), "Yeah I know her inside out...I know what each cry means, I know if she's in pain and I know if she's just got the hump, I know if she wants attention and I know if she's hungry. She has a different cry for everything” (P5).

\section{Learning and Child Development}

There were qualitative differences in people's views on knowledge of child development. Many of those interviewed said it was important to be able to recognise developmental changes and respond accordingly and parents largely welcomed this as a learning experience, "you see all these programs and you should be doing things this way or that way, there is no right way of doing anything is there? ...I suppose you learn from other people's experiences to a certain extent" (P2), "you are constantly learning... you are learning how to be a parent" (P2), "you should know what to do and that isn't the case and it is constant, you do need help right the way through" (P3). Health visitors also talked about child development and emphasised the lack of awareness that they had experienced amongst parents, “they've got this illusion that a child's basically awake for about four hours" (HV2), "people haven't got any clue about young children's stages they go through and their development" (HV2), "they don't understand developmentally where the child is at, a lack of knowledge about really where the child is at a certain age" (HV3). For a number of family support workers the concern was that parents may not always have an understanding of child development, "the newness of each stage of development, the lack of confidence that 
can give you as a person" (FW2), "lack of understanding of ordinary child development" (FW2), "how children learn through play... parents don't recognise that they are the first teachers of their children" (FW1).

\section{Feelings of failure}

Failure, guilt and the need to be a 'good enough' parent were common themes among all those interviewed. Parents identified a number of issues, "she was being very stroppy towards me and I blamed myself" (P1), "I felt I was a terrible mother" (P3), "everyone at some point must feel a hopeless parent" (P2). It was said by one of the Asian women, "I spoke to her in my language and once she went to nursery I felt a failure because she couldn't speak English" (P4).

Health visitors and family support workers also identified a number of these issues, " $m y$ child doesn't like me therefore I am not good enough" (HV1), "they feel a failure and they think it's only them who are, you know, struggling and that everybody else is coping" (HV2), "the parent will sometimes get quite upset because the child isn't doing something...they are thinking they should be able to because Johnny down the road is" (HV3), "they blame themselves for everything... what am I doing to my child?" (FW3), "I haven't had one parent who thinks that they have done a good job...there is such an expectation of what a good parent is because of the media and because of your peer group...most of them think they are terrible, terrible parents" (FW4).

\section{Effective Parenting}


All groups agreed that it was important for parents to feel effective in the parenting role and a number of themes emerged around the notion of effective parenting (Box 3). These themes were raised both in response to the question; 'how would you describe a good day?' and also when participants were asked specifically to discuss their views on effective parenting.

\section{Insert Box 3}

\section{Happy children}

To have 'happy children' was considered by all groups to be an important ingredient of effective parenting, "having a happy child, a child that enjoys their life...to ensure that they have a happy life by providing them with care, support, attention" (P1), "happy children, if you manage that you are doing really well" (P3).

\section{Achieving}

Several groups also said it was important to enable children to achieve or to reach their full potential, "not just to talk in English, to be able to talk in our own language, to me that would be a big achievement" (P4), "enabling them to be effective and independent adults and achieve their full potential" (P1).

\section{Understanding child's needs}

The importance of understanding and responding to their child's needs was of particular importance to parents and was raised when discussing the difficulties of parenting as well as contributing to effective parenting, "I think listening and really trying to 
understand where your child is coming from, so that your response to what they need, or what they've done is kind of appropriate" (P1), "to be everything to them at once, all at once you know, the strong person, the listening ear for them...” (P3).

\section{Willingness to change, Acceptance}

Several groups identified 'a willingness to change' as crucial to being effective as a parent, "being willing to try different ideas I think and discuss where things are going wrong" (P2), "most of them think that it's something that the child has to change, some see it as they've got to make some changes" (HV2). A number of groups suggested that accepting yourself as 'good enough' and having realistic expectations was also important, "being a good enough parent" (HV2), "with realistic expectations" (HV3), "feeling good about themselves as a parent" (FW2), "acknowledging where they are at and how well they have done so far", (FW3), "to know that there is no such thing as a perfect parent...not trying to get perfection” (FW4).

\section{Discussion}

This study reflects the views and experiences of mothers of children up to six years of age and of health visitors and family support centre workers who work with those mothers. It provides insights and alternate accounts of parenting experiences and what parents' expectations are that both compliment and add to policy guidance. The findings support the consultation with young people that preceded the recent green paper 'Every Child Matters' in the areas that young people themselves perceive as important outcomes for them i.e. staying safe, being healthy, enjoying and achieving, making a positive contribution, and economic well-being (Department for Education 
and Skills, 2003). From our data it would seem that these are outcomes that mothers, not surprisingly, also want for their children. These outcomes are at the heart of effective parenting from the mother's perspective. The evaluation of SureStart (SureStart, 2001) that used a qualitative approach, focused on parental views of the services put in place rather than how they, as parents, felt enabled to become effective. Our study would suggest that if the services provided by such initiatives as Sure Start and other parenting programmes are acceptable to parents then in order to achieve the perceived outcome of effective parenting it is important to start from the parent's perspective.

This study also explicitly used a framework (self-efficacy) that grounds the study theoretically, enabling further development and refinement within this construct. Consistent with other studies (Barlow \& Stewart-Brown, 2001, Long et al., 2001, Grimshaw \& McGuire, 1998) themes surrounding behaviour problems and discipline, handling conflicts, making time for themselves and the children, relationships and knowledge were all perceived to be important issues. However, our data revealed qualitative differences in the importance given to these issues and the frequency with which they were discussed. While professionals, especially health visitors, perceived behavioural management to be a major concern for parents, parents themselves viewed empathy with and understanding of children, and the notions of 'happy, confident children' and 'feeling good about yourself as a parent' to be equally important.

As discussed in US research (Coleman \& Karraker, 1997, 2000, Cutrona \& Troutman, 1986, Raver \& Leadbeater, 1999, Teti \& Gelfand, 1991) the focus group findings have highlighted that parents' self-efficacy beliefs may be key to their behaviour in the 
parenting role and to both the behaviour and well-being of their children. This is an important indicator for the development of UK parenting programmes.

Similarly, US studies that have found a relationship between parenting self-efficacy beliefs and parenting behaviour have largely been undertaken on homogenous samples (Cutrona \& Troutman, 1986, Gross et al., 1999, Jackson, 2000, Jackson \& Huang, 2000). In this UK based study we were able to include mothers from a wide range of cultural, social and educational backgrounds and it is evident from the discussions that the issues raised are relevant to most mothers regardless of age or background. However, in addition to the challenges faced by many mothers, there were additional issues raised by parents from Asian communities and from the young mothers' group. Although the challenges and difficulties discussed were common among all groups, there were differences between groups in how these were expressed. Discipline, which was a major issue for all groups, was expressed by health visitors and family centre workers in terms of setting and maintaining of boundaries, while parents talked more about the negative feelings associated with disciplining their child.

Parents discussed their perceived ability to manage their children in a wide range of circumstances, and consistent with self-efficacy theory, those who believed in their own abilities said they were more likely to persevere in a given task.

A limitation of qualitative studies is that samples tend to be small. However, the aim of this exploratory study was not to be a probability driven survey but to elicit a deep understanding of the opinions and experiences of parents and those who work with parents. We believe this is the first UK study to use a self-efficacy framework in this way. The mothers in this study were drawn from a range of social and ethnic backgrounds, however fathers were not represented. As with other research of this 
nature, the sample was self-selecting. Parents were invited by letter to participate in the focus groups and no fathers consented to take part, making it difficult to draw conclusions about father's views and experiences. Mothers who took part were mostly from parenting programme waiting lists and it is therefore acknowledged that the findings will not be generalisable to all parents. The mothers in this study, who had a diverse range of views and experiences, identified a breadth of issues around parenting and we are therefore confident that the findings are transferable to other groups of mothers. Drawing on the ideas of Perakyla (Perakyla, 1997), cited by Gobo (Gobo, 2004), the transferability of evidence is an expression not of what all mothers would perceive as parenting issues, but what all mothers could perceive as parenting issues. Our confidence is based on the systematic and rigorous approach to organising and conducting the focus groups, the use of two moderators, the verbatim transcription of mothers' discussions with us and the inter-rater consistency in the thematic analysis of the data. This is expressed by authors such as Lincoln and Guba as an 'audit trail' (Lincoln \& Guba, 1985) that can be tracked by the user of the research or other investigators. Using focus groups was a meaningful way to explore how parenting is perceived by mothers and by professionals who work with families and to capture the experiences of parents from different cultural, social and educational backgrounds. Given the above limitations these findings contribute to our understanding of parenting and parenting self-efficacy in the UK context. We believe that these data provide new insights into mother's perceptions of their abilities and difficulties as well as the perceptions of programme facilitators. Bearing in mind the political will to be more responsive to families (Department for Education and Skills, 2003) it is important that 
any interventions developed to support parenting acknowledge mother's perceptions and build this into their evaluation strategies.

\section{Acknowledgements:}

The work was funded by a grant from the Primary Care Research Network for Hertfordshire (HertNet). Opinions and conclusions are those of the authors and not the funders. We are indebted to the parents, health visitors and family support workers who took part in the focus groups and to the family support centres and clinics that provided venues and creche facilities for the focus groups. 


\section{References}

Acheson D., Baker D. \& Illsley R. (1998) Inequalities in health, BMJ, 317, 1659.

Barlow J. (1999) Systematic review of the effectiveness of parent-training programmes in improving behaviour problems in children aged 3 - 10, Health Services Research Unit, Department of Public Health, Oxford.

Barlow J. \& Stewart-Brown S. (2001) Understanding parenting programmes: Parent's views, Primary Health Care Research and Development, 2, 117-130.

Brody G., Flor D. \& Gibson N. (1999) Linking maternal efficacy beliefs, developmental goals, parenting practices and child competence in rural single-parent African American families, Child Development, 70, 1197-1208.

Bryman A. \& Burgess R. (1994) Analysing qualitative data, Routledge, London.

Burgess R. (1994) In Field research: a sourcebook and field manual.(Ed, Burgess) Routledge, London.

Chiariello M. \& Orvashel H. (1995) Patterns of parent-child communication: Relationship to depression, Clinical Psychology Review, 15, 395-407.

Coleman P. \& Karraker K. (1997) Self-efficacy and parenting quality: Findings and future applications, Developmental Review, 18, 47-85.

Coleman P. \& Karraker K. (2000) Parenting self-efficacy among mothers of school-age children: Conceptualization, measurement and correlates, Family Relations, 49, 13-24.

Cunningham C.E. \& Boyle M.H. (2002) Preschoolers at risk for attention-deficit hyperactivity disorder and oppositional defiant disorder: Family, parenting, and behavioural correlates, Journal of ABnormal Child Psychology, 30, 555-569.

Cutrona C. \& Troutman B. (1986) Social support, infant temperament and parenting self-efficacy: A mediational model of postpartum depression, Child Development, 57, 1507-1518.

Department for Education and Skills (2003) Every Child Matters. London: DfES.

Donovan W., Leavitt L. \& Walsh R. (1990) Maternal self-efficacy: Illusory control and its effect on susceptibility to learned helplessness, Child Development, 61, 1638-1647.

Ehrensaft M.K., Wasserman G.A., Verdelli L., Greenwald S., Miller L.S. \& Davies M. (2003) Maternal antisocial behaviour, parenting practices, and behavioural problems in boys at risk for antisocial behaviour, Journal of Child and Family Studies, 12, 27-40.

Gaze H. (1997) All in the family, Health Visitor, 70, 332-333.

Gibbs J., Underdown A. \& Liabo K. (2003) Group-based parenting programmes can reduce behaviour problems of children aged 3-10, What works for Children group Evidence Nugget.

Gobo G. (2004) In Qualitative Research Practice(Eds, C, S., G, G., J, G. and D, S.) Sage, London.

Grimshaw R. \& McGuire C. (1998) Evaluating parenting programmes: A study of stakeholder's views, National Children's Bureau, London.

Gross D., Conrad B., Fogg L. \& Wothke W. (1994) A longitudinal model of maternal self-efficacy, depression, and difficult temperament during toddlerhood, Research in Nursing and Health, 17, 207-215.

Gross D., Fogg L. \& Tucker S. (1995) The efficacy of parent training for promoting positive parenttoddler relationships, Research in Nursing and Health, 18, 489-499.

Gross D., Sambrook A. \& Fogg L. (1999) Behaviour problems among young children in low-income urban day care centres, Research in Nursing and Health, 22, 15-25.

Holloway I. \& Wheeler S. (1996) In Qualitative research for nurses(Ed, Wheeler, H.) Blackwell Science, Oxford.

Home Office (1998) Supporting families: A consultation document, Home Office, London.

Jackson A. (2000) Maternal self-efficacy and children's influence on stress and parenting among single black mothers in poverty, Journal of Family Issues, 21, 3-16.

Jackson A. \& Huang C. (2000) Parenting stress and behavior among single mothers of preschoolers: The mediating role of self-efficacy, Journal of Social Science Research, 26, 29-42.

Krueger R. \& Casey M. (2000) Focus Groups; A practical guide for applied research, Sage, London.

Kwok S. \& Wong D. (2000) Mental health of parents with young children in Hong Kong: The roles of parenting stress and parenting self-efficacy, Child and Family Social Work, 5, 57-65. 
Lincoln Y.S. \& Guba E.G. (1985) Naturalistic Enquiry, Sage, CA.

Long A., McCarney S., Smyth G., Magorrian N. \& Dillon A. (2001) The effectiveness of parenting programmes facilitated by health visitors, Journal of Advanced Nursing, 34, 611-620.

Miller S. \& Sambell K. (2003) What do parents feel they need? Implications of parent's perspectives for the facilitation of parenting programmes, Children \& Society, 17, 32-44.

Morgan D.L. (1998) The focus group handbook, Sage, Thousand Oaks, CA.

National Centre for Social Research (1999).

Patterson G.R., DeBaryshe D. \& Ramsey E. (1989) A developmental perspective on antisocial behaviour, American Psychologist, 44, 329-335.

Perakyla A. (1997) In Qualitative Research(Ed, D, S.) Sage, London.

Raver C. \& Leadbeater B. (1999) Mothering under pressure: Environmental, child, and dyadic correlates of maternal self-efficacy among low-income women, Journal of Family Psychology, 13, 523534.

Secretary of State for Health (1999) Stationery Office, London.

Serketich W. \& Dumas J. (1996) The effectiveness of behavioral parent training to modify antisocial behaviour in children: A meta-analysis, Behavior Therapy, 27, 171-186.

SureStart (2001) Sure Start unit, London.

Teti D. \& Gelfand D. (1991) Behavioural competence among mothers of infants in the first year: The mediational role of maternal self-efficacy, Child Development, 62, 918-929.

Willgerodt M.A. (2003) Using focus groups to develop culturally relevant instruments, Western Journal of Nursing Research, 25, 798-814. 
Box 1. Challenges of parenting

- Expectations of others, Pressures

- Play, Managing time, Establishing Routines

- Being Prepared for Motherhood

- Consistent parenting

- Cultural Expectations 
Box 2. Difficulties of parenting

- Boundaries

- Behaviour issues and Discipline

- Handling conflicts, Battles

- Communicating with child, Listening and Responding

- Learning, Knowledge of Child Development

- Feelings of failure 
Box 3 Effective Parenting

- Happy children

- Achieving

- Understanding child's needs

- Willingness to change, Acceptance 